\title{
DEVELOPMENT OF GEOSPATIAL MAP BASED PORTAL FOR DELIMITATION OF MCD WARDS
}

\author{
Amit Kumar Chandra Gupta ${ }^{\mathrm{a}}$, Pawan Kumar ${ }^{\mathrm{b}}$, Pawan Kumar Sharma ${ }^{\mathrm{c}}$ \\ ${ }^{\mathrm{a}}$ Geospatial Executive - amitkc.gis@gmail.com, ${ }^{\mathrm{b}}$ Software Developer - pawankr82@gmail.com, \\ ${ }^{\mathrm{c}}$ Managing Director (IAS) - secyit@nic.in \\ Geospatial Delhi limited, Department of Information Technology, Ministry of Communications and Information Technology
}

\begin{abstract}
KEY WORDS: Geospatial Map based Portal for Delimitation of MCD Wards (GMPDW), Spatial Decision Support System (SDSS), Enumeration Block (EB), Enumeration Block Group (EBG), Virtual Private Network (VPN), Special Purpose Vehicle (SPV)
\end{abstract}

\begin{abstract}
:
The Geospatial Delhi Limited (GSDL), a Govt. of NCT of Delhi Company formed in order to provide the geospatial information of National Capital Territory of Delhi (NCTD) to the Government of National Capital Territory of Delhi (GNCTD) and its organs such as DDA, MCD, DJB, State Election Department, DMRC etc., for the benefit of all citizens of Government of National Capital Territory of Delhi (GNCTD).

This paper describes the development of Geospatial Map based Portal for Delimitation of MCD Wards (GMPDW) and election of 3 Municipal Corporations of NCT of Delhi. The portal has been developed as a map based spatial decision support system (SDSS) for delimitation of MCD Wards and draw of peripheral wards boundaries to planning and management of MCD Election process of State Election Commission, and as an MCD election related information searching tools (Polling Station, MCD Wards and Assembly constituency etc.,) for the citizens of NCTD. The GMPDW is based on Client-Server architecture model. It has been developed using Arc GIS Server 10.0 with .NET (pronounced dot net) technology. The GMPDW is scalable to enterprise SDSS with enterprise Geo Database \& Virtual Private Network (VPN) connectivity.

Spatial data to GMPDW includes Enumeration Block (EB) and Enumeration Blocks Group (EBG) boundaries of Citizens of Delhi, Assembly Constituency, Parliamentary Constituency, Election District, Landmark locations of Polling Stations \& basic amenities (Police Stations, Hospitals, Schools and Fire Stations etc.). GMPDW could help achieve not only the desired transparency and easiness in planning process but also facilitates through efficient \& effective tools for management of MCD election. It enables a faster response to the changing ground realities in the development planning, owing to its in-built scientific approach and openended design.
\end{abstract}

\section{INTRODUCTION}

India is a constitutional democracy with a parliamentary system of government, and at the heart of the system is a commitment to hold regular, free and fair elections. These elections determine the composition of the government, the membership of the two houses of parliament, the state and union territory legislative assemblies, and the Presidency and vice-presidency. Elections are conducted according to the constitutional provisions, supplemented by laws made by Parliament. The Election Commission has the residuary powers under the Constitution to act in an appropriate manner. State Election Commission is a constitutional authority for conducting the MCD election in all MCDs of National Capital Territory of Delhi.

The National Capital Territory of Delhi (NCT) comprises three local bodies, MCD, NDMC and Cantonment Board. Delhi MCD is further divided into 3 MCD Corporations North Delhi Municipal Corporation, South Delhi Municipal Corporation, and East Delhi Municipal Corporation. Sate election commission of Delhi is also conducting the delimitation of MCD wards after each CENSUS enumeration completion. The wards redraw is required for population equalization in each ward before the MCD wards election.

The Geographical Information System (G.I.S.) plays a vital role for systematic, non-discrimination and transparent functioning of delimitation process of State Election Commission of NCT of Delhi. GIS has facilitated to State Election Commission for redrawing of the wards boundary and management of MCD election in all ways as a spatial decision support system (SDSS) with thematic map representation as well as map based web application by using the spatial \& non spatial data.

\subsection{Problem at Hand}

The Enumeration Block (EB) is the smallest (group of houses) area unit of CENSUS department. Each EB is heaving an handmade location map (thematic map without scale), Extent area address, and population and other demographic data. The whole data is in the format of hard copy papers. The digitalization of the CENSUS data and linking the corresponding data with it in terms of spatial and non-spatial data is a herculean task. The voluminous nature of data involved for proper record keeping is indeed cumbersome and cannot effectively be handled by traditional system of record keeping. The analogue system means acceptance of inflexibility resulting from data storage in fixed forms and formats. The system becomes less useful for many purposes and is rarely updated because of costs implication. The maps are easily displaced or destroyed because different people at different locations use them. An alternative approach taking into the account of limitations faced by the traditional system is of maintaining a coherent database in a scientific and efficient manner by use of advanced information technology is therefore, required. Hence, there will be improvements in planning, implementation and operation of the election department 
through provision of timely, reliable, sufficiently and accurately detailed data which will facilitate its decision making activities. This paper describes the development of Geospatial Map based Portal for Delimitation of MCD Wards (GMPDW) of NCT of Delhi. The portal has been developed as a map based spatial decision support system (SDSS) for pertain to delimitation of wards and MCD election management of State Election Commission, and as an election related information searching tools (Enumeration Block boundaries, Polling Station and Assembly constituency etc.,) for the citizens of NCTD. It enables a faster response to the changing ground realities in the development planning, owing to its in-built scientific approach and open-ended design. The GMPDW is based on Client-Server architecture model. It has been developed using Arc GIS Server 10.0 with .NET on Microsoft Windows environment. The GMPDW is scalable to enterprise SDSS with enterprise Geo Database \& Virtual Private Network (VPN) connectivity.

\section{STUDY AREA}

28.61o N, 77.23o E is the geographical location of NCT of Delhi. NCT of Delhi is divided into three (3) Municipal Corporations. Total 70 Assembly Constituencies and 7 Parliamentary Constituencies are in NCT of Delhi.

\subsection{Spatial Data Dictionary}

Geospatial Delhi Limited (GSDL), a Govt. of NCT of Delhi Company, is a Geo-Knowledge enterprise, initially formulated as a Special Purpose Vehicle (SPV) to facilitate the Delhi State Spatial Data Infrastructure (DSSDI) Project. Each and every building and other spatial features (Like Buildings, Roads, Parks, Natural features etc) of NCT of Delhi has been captured in DSSDI project. The property data base was collected through field survey supplemented with concerned departmental inputs. This huge data is updating continuously by GSDL day by day. By using this data as a base layer and CENSUS data (non spatial data) GSDL has created the electoral spatial layers (Enumeration Blocks \& Enumeration Block Group Boundary, MCD Wards Boundary, Assembly Constituency Boundary, Election point Layers- Polling Stations, CEO Office, DEO Offices, SDM Election Offices, ERO \& AERO Offices, Voter Centres, and Counting Centres). These features represent the essential components of spatial database over which all secondary spatial as well as non-spatial information are superimposed for query/analysis and generation of thematic maps.

\subsection{Spatial Database Creation}

As per the methodology and guidelines described above, stateof-the-art Arc GIS Server 10.0 has been used for creation of the required spatial database in digital form. The digitized map information is stored in the GIS database appropriately in the form of layers, each layer representing a unique entity in the spatial data dictionary.

\section{GIS PLATFORM}

ESRI Arc GIS Server 10.0 provides a standard framework for developing GIS applications. Arc GIS Server is both robust and extensible and its rich functionality allows developers to concentrate on solving organizational problems, not building GIS functionality from scratch. Arc GIS Server is based on Object oriented Framework. Arc GIS Server Objects support for simple map dialog boxes, multithreaded servers, and complex Windows desktop applications.

\subsection{Key features of Arc GIS Server}

Cost-effective deployment: Arc GIS Server Runtime is licensed per computer. This allows multiple Arc GIS applications to run on the same computer, incurring the cost of only a single runtime license.

Developer controls: Arc GIS Server provides a common set of developer controls that allow developers to easily deploy wellcrafted applications with a common look and feel. A common user experience leads to a short learning curve for users, so returns on the applications are quickly realized.

Cross platform functionality: Arc GIS Server application and all of its associated objects and controls are available on a wide variety of platforms including Windows, Linux. There is no need to change or add operating environments to the present computing infrastructure.

Dynamic display: It provides a mechanism for synchronized refreshing that allows moving objects, such as maps and graphics, to be displayed with fast refresh-rate technology.

Toolbars provide GIS tools, such as Pan, Zoom, Identify, Selection, and Editing, to interact with maps.

Developer tools: in Arc GIS Server include code projects, wizards, templates, and code snippets that integrate with your integrated development environment (IDE) to help you create custom desktop GIS applications.

\subsection{Application Architecture}

The architecture has been considered for the implementation of Geospatial Map based portal for Delimitation of MCD Wards (GMPDW) is scalable to enterprise DSS with enterprise Geodatabase \& VPN connectivity as shown in Fig. 1. Authenticate user access control is ensured by VPN \& database security by using enterprise Geo-database.

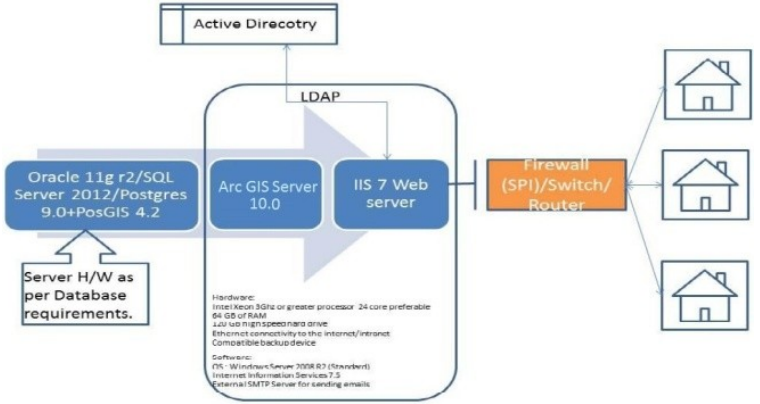

Figure 1 Enterprise Architecture

\subsection{Development Environment}

Arc Objects classes library is used in Server SDK environment using J2EE as front-end.

\section{DEPLOYMENT ENVIRONMENT}

\subsection{Installation of Arc GIS Server Runtime}

Arc GIS Server software-based applications require that Arc GIS Server Runtime be installed on the end user's machine. Installation of the runtime can be handled in either of two ways:

1. End user runs the Arc GIS Server Runtime setup directly from the CD.

2. Arc GIS Server Runtime setup can be included within our own application's installation program 


\subsection{Authorization of the Arc GIS Server Runtime}

The mechanism used to license the Arc GIS Server Developer Kit on a per-machine, single use basis via an ESRI Copy Protection (*.ecp) file.

\subsection{Application Deployment}

After arranging the shape files layers in proper sequence, the map is deployed in web platform by using Arc GIS web application platform.

\section{GEOSPATIAL MAP BASED PORTAL FOR DELIMITATION OF MCD WARDS FEATURES}

The following functions have implemented in Geospatial Map based portal for Delimitation of MCD Wards (GMPDW) for user use. These functions have made the geo data more accessible, analyzing in the application.

> Display a map with multiple map layers, such as roads, streams and boundaries.

$>$ Pan and zoom throughout a map.

$>$ Draw graphic features such as points, lines, ellipses, rectangles and polygons.

$>$ Draw descriptive text.

$>$ Identify features on a map by pointing at them.

$>$ Select features along lines and inside boxes, areas, polygons, and circles.

$>$ Select features within a specified distance of other features

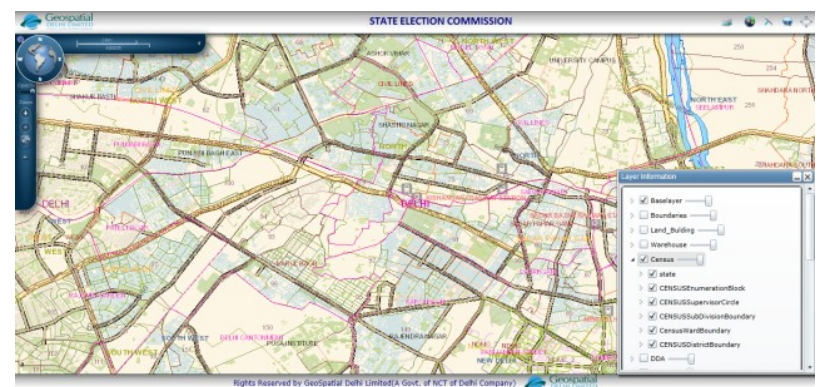

Figure 2 GMPDW, Front Page (Thematic Map)

\section{DELIMITATION OF MCD WARDS}

\subsection{Factors follows in delimitation}

The following factors have followed for delimitation of MCD wards:-

$>$ Geospatial maps and data from Census of India has taken as a primary data for the purposes of delimitation

$>$ As per Census 2011 the average population per ward comes to approx 60,000

$>$ Average population variation to be between 10 to $15 \%$ in the ward.

$>$ Boundary of ward to be within the boundary of the Assembly Constituency.

$>$ Boundary of ward should be clearly defined along $\mathrm{road} / \mathrm{drain} /$ railway line so that there is no confusion about the boundary of the ward

$>$ A colony or slum cluster would be kept within a ward. If a colony/cluster falls in two assembly constituencies, the status quo will be maintained since assembly boundaries cannot be crossed

\subsection{Enumeration Blocks \& Enumeration Blocks Group Boundary Creation}

As per the reference of handmade Enumeration Blocks maps provided from CENSUS, GSDL has spatially created the EB \& EBG boundary GIS layer.
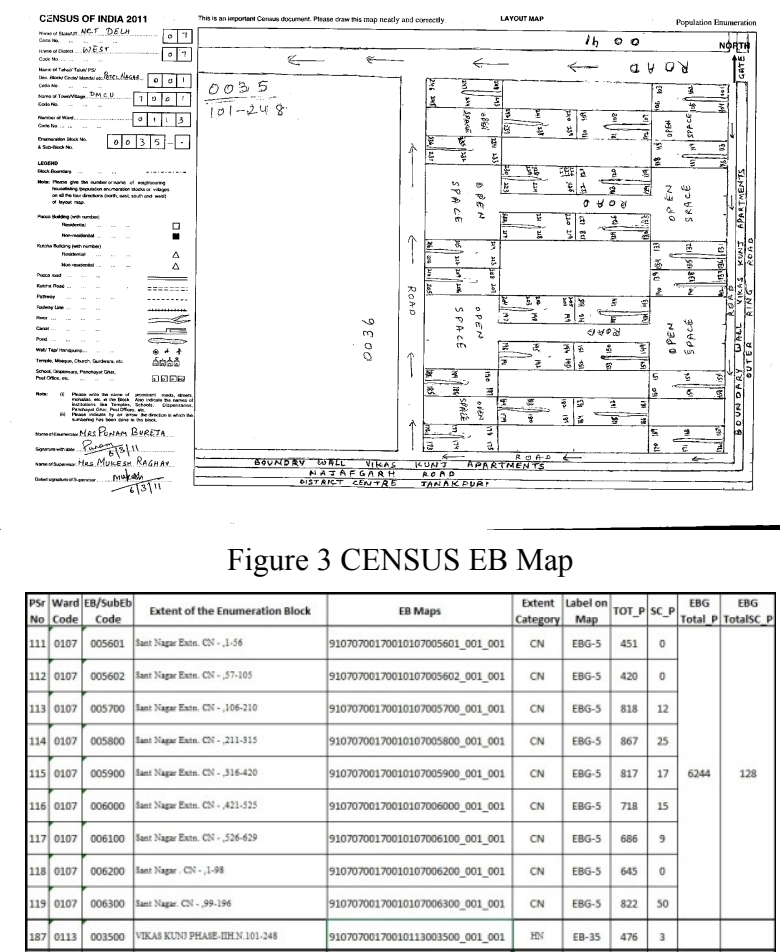

Figure 4 CENSUS EB Extent \& Population Sheet

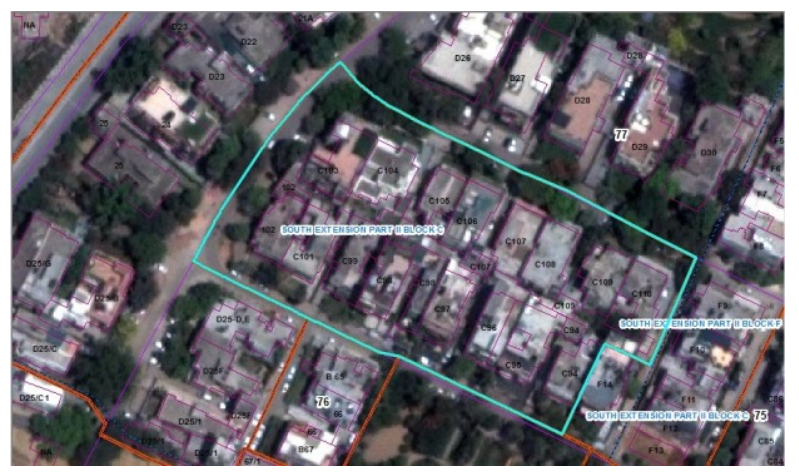

Figure 5 Demarcated EB Boundary

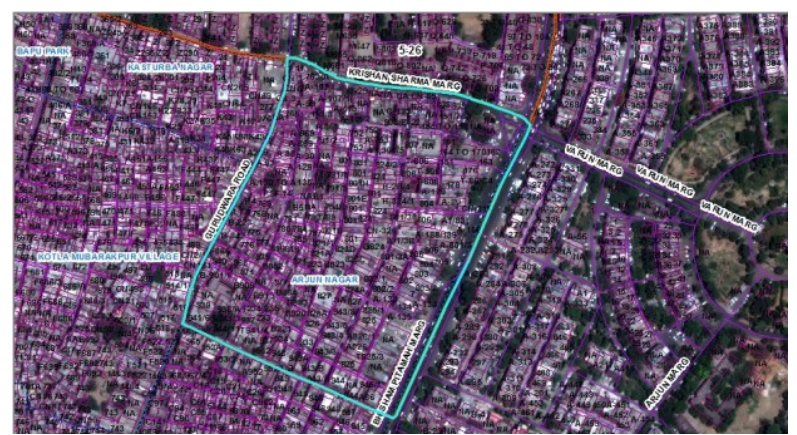

Figure 6 Demarcated EBG Boundary 


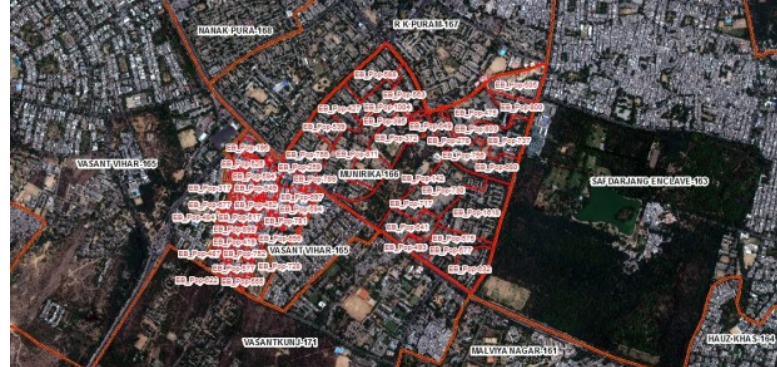

Figure 7 EB \& EBG Boundaries with Population

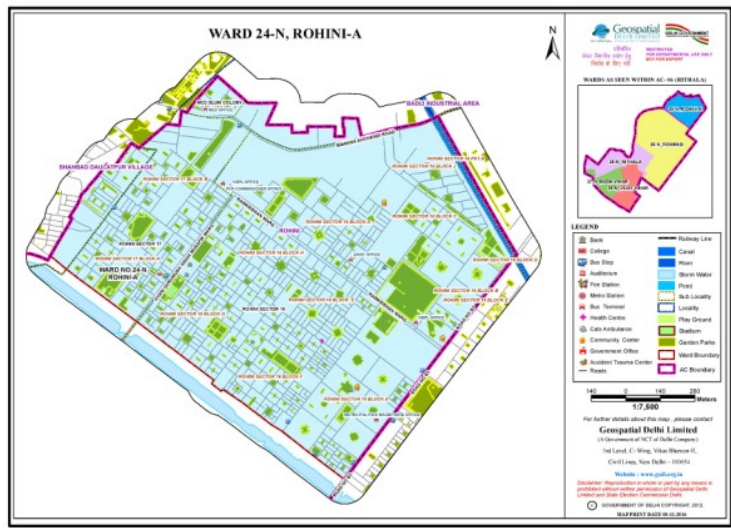

Figure 8 Delimited Ward Map ${ }^{1}$

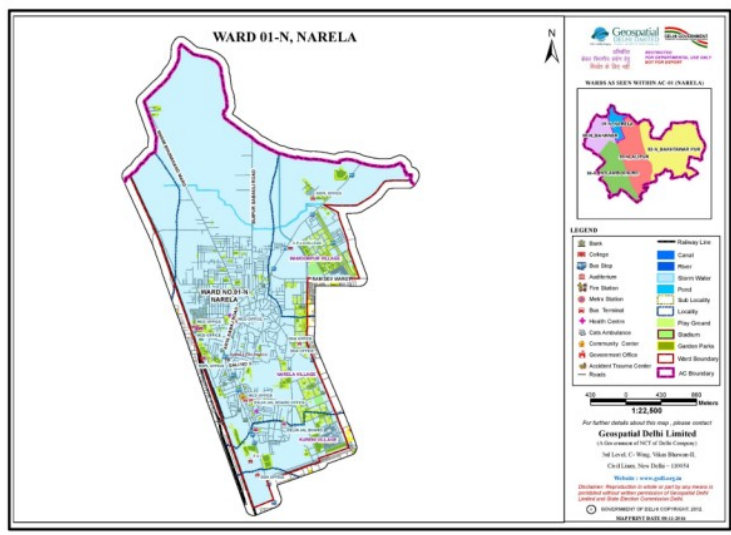

Figure 9 Delimited Ward Map ${ }^{2}$

7. CONCLUSION

This study is a Geospatial Map based portal for Delimitation of MCD Wards (GMPDW) that provides access, analysis, and new layer creation to spatial datasets for delimitation of MCD wards. It is designed to allow viewing, querying, and analysis of geographic information. There are two aspects of the Internet GIS. One is the web-based application and the other is Server/Client balance. This application is a software independent system that users do not have to buy any GIS software and do not have to read manuals to use it but they can access GIS data and analysis functions over the Internet. It offers maximum functionality with the minimum effort. It provides a transparent, non-discrimination, easy-access virtual platform for delimitation of wards process. The commission has easily presented and effectively described the delimited wards to citizens (political leaders) in public consultation process.
State Election Commission has effectively managed the MCD election process with heaving the new wards.

The drawback in such a distributed system is that data come from different sources based on different forms which cause havoc in a GIS. It is necessary to compile data before the development of the application.

The response time for generating maps is related to the map server configuration (memory, disk, and processor). The map is also depending on the network connection. It can take a while to download the maps. In addition, system downtime for maintenance and updates for a web site is unavoidable. But this system is designed for easy maintenance and repair without interruption.

\section{ACKNOWLEDGEMENT}

The authors are thankful to Sh. Rakesh Mehta Ji, Commissioner, State Election Commission, NCT of Delhi for his constant support and encouragement.

\section{REFERENCES}

Building Enterprise DSS Using ARC GIS Engine Geoamphere: A CASE STUDY, Vivek Chitale, M. Vinayak Rao, Geetanjali Mehta, Dhrubjyoti Sarma, N. Dhanasekar

White paper on Arc Engine 9.2 development (http://resources.esri.com/Arc GISengine) 